\section{Biodiversity and ecosystem functioning: exploring large-scale patterns in mainland China}

\author{
Jin-Tun Zhang ${ }^{(1)}$, Cuihong Wang ${ }^{(2)}$
}

Relationships between biodiversity and ecosystem functioning are vital to understand ecosystem properties, and have frequently been addressed in smallscale studies. However, interactions and changes differ at large scales, and should be similarly evaluated to monitor biodiversity and ecosystem functional alterations. In the present study, Mainland China was divided into 241 quadrats of $2^{\circ}$ latitude by $2^{\circ}$ longitude. Ecosystem function was comprehensively assessed using three indicator variables in each quadrat, primary productivity, bird species richness, and relative humidity. Relationships between each ecosystem function variable were regressed against seed plant species richness. All three indicators exhibited the same change model, a linear model when plant species richness was under 5.000 species, and a hump-back/quadratic model when seed plant richness was over 5.000 species, with an increase in seed plant species richness at a larger scale.

Keywords: Ecosystem function, Seed plants, Species richness, Model, China

\section{Introduction}

Ecosystem function is the capacity for natural processes and components integral to those processes to provide goods and services, which ultimately meet human needs, either directly or indirectly (de Groot et al. 2002). Indirectly, these services provide refuge and reproductive habitat to wild plants and animals. Many studies have demonstrated the importance of biodiversity to ecosystem functioning, and primary productivity has been representative of ecosystem function (Thompson et al. 2005, Grace et al. 2007). Primary productivity is the rate at which plants and other photosynthetic organisms (e.g., phytoplankton, macroalgae) produce organic compounds i.e., biomass in an ecosystem.

A persistent debate continues regarding the relevance of studies that underlie the conclu-

$\square$ (1) College of Life Sciences, Beijing Normal University, 100875 Beijing (China); (2) College of Environment and Resources, Shanxi University, 030006 Taiyuan (China)

@ Jin-Tun Zhang (Zhangjt@bnu.edu.cn)

Received: Apr 14, 2012 - Accepted: Jul 20, 2012

Citation: Zhang JT, Wang C, 2012. Biodiversity and ecosystem functioning: exploring large-scale patterns in Mainland China. iForest 5: 230-234 [online 2012-1002] URL: http://www.sisef.it/ iforest/contents?id=ifor0627-005

Communicated by: Marco Borghetti sions explaining biodiversity and functioning in mature natural ecosystems. Most experimental studies of constructed species assemblages determined that increasing diversity contributes to greater biomass production (e.g., Hooper et al. 2005, Spehn et al. 2005). Alternatively, species reduction experiments in natural systems revealed biomass was resilient to decreased biodiversity (Smith et al. 2004, Suding et al. 2006), while Foster et al. (2004) demonstrated during species addition experiments that species pools or communities were integral to increased biomass. These experiments were comparatively small. For large-scale studies, the productivity gradient was very often associated with plant diversity. In most cases, a unimodal (also called "hump-back" or "humped-backed") relationship emerged, which exhibited the highest productivity at intermediate diversity levels (Grace 1999, Keddy 2005). This approach rapidly gained enthusiastic popularity among ecologists, and was soon widely recognized as a general empirical relationship (e.g., Begon et al. 1996). Although later studies reported positive or negative response patterns, the unimodal relationship remains the most commonly reported in plants (Hector et al. 1999, Waide et al. 1999, Mittelbach et al. 2001, but see Gillman \& Wright 2006).

In the present study, we explored the relationship between plant ecosystem biodiversity, and three potential ecosystem function indicators (primary productivity, bird species richness, and annual mean relative humidity) at a large scale in Mainland China.

\section{Materials and methods}

Mainland China was divided into 241 quadrats (including Hainan Island as one quadrat), each $2^{\circ}$ latitude by $2^{\circ}$ longitude (approximately $36450 \mathrm{~km}^{2}$ ). If a quadrat had an area less than half a standard quadrat on national boundaries, it would be merged into its neighboring quadrat (Zhang 2002). A small geographic region such as a $2^{\circ}$ latitude by $2^{\circ}$ longitude quadrat would typically be characterized as a group of ecosystems (Zhang 2002, Zhang et al. 2006). However, ecosystems in the quadrats were similar in composition, structure, and inter- and intra-environments, and correspondingly similar in function (Zhang \& Dong 2010). Therefore, for the purposes of this study, we assumed the relationship between biodiversity and ecosystem functions could be evaluated at the quadrat level. Seed plant and bird species occurring in each quadrat were counted based on available records (e.g., national flora and fauna, provincial flora, and local research literature, among other appropriate reference materials - Wu 1980, 1987, 2004, Chen 1993, Editor Committee of Fauna Sinica 1998, Northwest Research Institute of Botany 2000, Zheng 2005). Primary productivity of each quadrat was estimated by applying the following relationship (eqn. 1):

$$
P=3000 \cdot\left[1-e^{0.0009695(E-20)}\right]
$$

where $E$ was obtained as follows (eqn. 2):

$$
E=1.05 N / \sqrt{1+(1.05 N / L)^{2}}
$$

where $L=300+25 \mathrm{~T}+0.05 \mathrm{~T}^{2}, N$ is the annual precipitation, $L$ is the annual maximum evaporation, and $T$ the annual mean temperature in each quadrat (see Lieth \& Box 1972, Li et al. 1998). This equation was the best fit with least error in simulating primary productivity based on observed and remotely sensed data in China ( $\mathrm{Li}$ et al. 1998). For each quadrat, annual mean relative humidity, and climatic variables were obtained from 30 -year records representing 830 county meteorological stations. Average values were used if more than one meteorological station was located in a quadrat; if no meteorological stations were present in a quadrat, data from the nearest station in its neighbor quadrat was selected.

Regression analysis was chosen to assess the relationships between plant species richness and ecosystem function indicators, and analyzed using the SPSS statistical package (SPSS Inc., Chicago, Illinois, USA). AIC (Akaike's Information Criteria) was applied to compare different regression models as follows: $A I C=2 k-2 \ln (L)$, where $k$ is the parameter number, and $L$ is the maximized value of the likelihood function in the regression model (Akaike 1974). 
Tab. 1 - Comparison of regression results of linear and quadratic models in the analysis of relations between primary productivity of ecosys tem, species richness of bird and relative humidity with species richness of seed plant with and without the three highest quadrats in the mainland of China. $(x)$ : refers to species richness of seed plant; $(Y)$ : refers to primary productivity of ecosystem, species richness of bird and relative humidity respectively; (AIC): $2 k-2 \ln (L)$, where $k$ is the number of parameters in the regression model, and $L$ is the maximized value of the likelihood function for the regression model.

\begin{tabular}{|c|c|c|c|c|c|c|c|c|}
\hline Variables & $\begin{array}{l}\text { The } 3 \text { highest } \\
\text { quadrats }\end{array}$ & Model & Regression equation & $R^{2}$ & $\mathbf{P}$ & AIC & $\mathbf{F}$ & $\mathbf{P}$ \\
\hline \multirow{4}{*}{$\begin{array}{l}\text { Primary } \\
\text { productivity }\end{array}$} & \multirow[t]{2}{*}{ With } & Linear model & $Y=0.4123 x+447.95$ & 0.4995 & $<0.001$ & 12.225 & 8.982 & 0.000 \\
\hline & & Quadratic model & $Y=-0.0001 x^{2}+0.9998 x+144.01$ & 0.667 & $<0.001$ & 12.065 & 10.437 & 0.000 \\
\hline & \multirow[t]{2}{*}{ Without } & Linear model & $Y=0.4909 x+385.46$ & 0.5515 & $<0.001$ & 11.405 & 8.78 & 0.000 \\
\hline & & Quadratic model & $Y=-0.0002 x^{2}+1.1049 x+101.77$ & 0.669 & $<0.001$ & 12.032 & 10.302 & 0.000 \\
\hline \multirow{4}{*}{$\begin{array}{l}\text { Species richness } \\
\text { of bird }\end{array}$} & \multirow[t]{2}{*}{ With } & Linear model & $Y=0.0362 x+121.3$ & 0.1911 & $<0.001$ & 10.563 & 8.523 & 0.000 \\
\hline & & Quadratic model & $Y=-7 \mathrm{E}-06 x^{2}+0.0657 x+105.87$ & 0.2121 & $<0.001$ & 9.887 & 8.987 & 0.000 \\
\hline & \multirow[t]{2}{*}{ Without } & Linear model & $Y=0.0356 x+121.54$ & 0.1507 & $<0.001$ & 9.538 & 8.736 & 0.000 \\
\hline & & Quadratic model & $Y=-0.005 x^{2}+0.0934 x+94.844$ & 0.2046 & $<0.001$ & 10.203 & 9.02 & 0.000 \\
\hline \multirow{4}{*}{$\begin{array}{l}\text { Relative } \\
\text { humidity }\end{array}$} & \multirow[t]{2}{*}{ With } & Linear model & $Y=0.0079 x+52.686$ & 0.3453 & $<0.001$ & 8.683 & 9.868 & 0.000 \\
\hline & & Quadratic model & $Y=-3 \mathrm{E}-06 x^{2}+0.0198 x+46.547$ & 0.4727 & $<0.001$ & 8.657 & 7.986 & 0.000 \\
\hline & \multirow[t]{2}{*}{ Without } & Linear model & $Y=0.0095 x+51.454$ & 0.3819 & $<0.001$ & 8.23 & 9.431 & 0.000 \\
\hline & & Quadratic model & $Y=-0.0006 x^{2}+0.0219 x+45.723$ & 0.4709 & $<0.001$ & 8.509 & 7.505 & 0.000 \\
\hline
\end{tabular}

\section{Results}

Linear and quadratic models were compared in an analysis of the following relationships: ecosystem primary productivity, bird species richness, and relative humidity, each against plant species richness. Results indicated quadratic models were more robust (with smaller AIC) when all quadrat data were used, but linear models were better (with smaller AIC) when the three highest quadrats were excluded from the analysis (Tab. 1). A linear model could be chosen when plant species richness is less than 5000 species, and the quadratic model could be applied when plant species richness exceeds 5000 species (Tab. 1). Ecosystem primary productivity was significantly associated with plant species richness; and a hump-back model relationship between primary productivity and seed plant species richness was evident $\left(\mathrm{R}^{2}=0.6671, \mathrm{P}<0.001, \mathrm{n}=241\right.$ Fig. 1). Primary productivity exhibited steep increases within the first 2000 seed plants, and continued to increase until reaching a maximum biomass of $2100 \mathrm{~g} \mathrm{~m}^{-2}$ at 3500 species (Fig. 1). Productivity decreased when the number of seed plants was over 4000 species. Bird species richness was also significantly correlated with plant species richness in mainland China $\left(\mathrm{R}^{2}=0.2121, \mathrm{P}\right.$ $<0.001, \mathrm{n}=241$ - Fig. 2). The number of bird species increased rapidly as seed plant species richness reached 1000 species; and subsequent slow increases occurred until reaching the maximum number of plant species (i.e., 5000). The relationship between bird and plant species richness also followed a loosely defined hump-back model.

Results depicted a close relationship between relative humidity and the number of seed plant species in mainland China $\left(\mathrm{R}^{2}=\right.$ $0.4727, \mathrm{P}<0.001, \mathrm{n}=241$ - Fig. 3 ). The number of seed plant species increased with
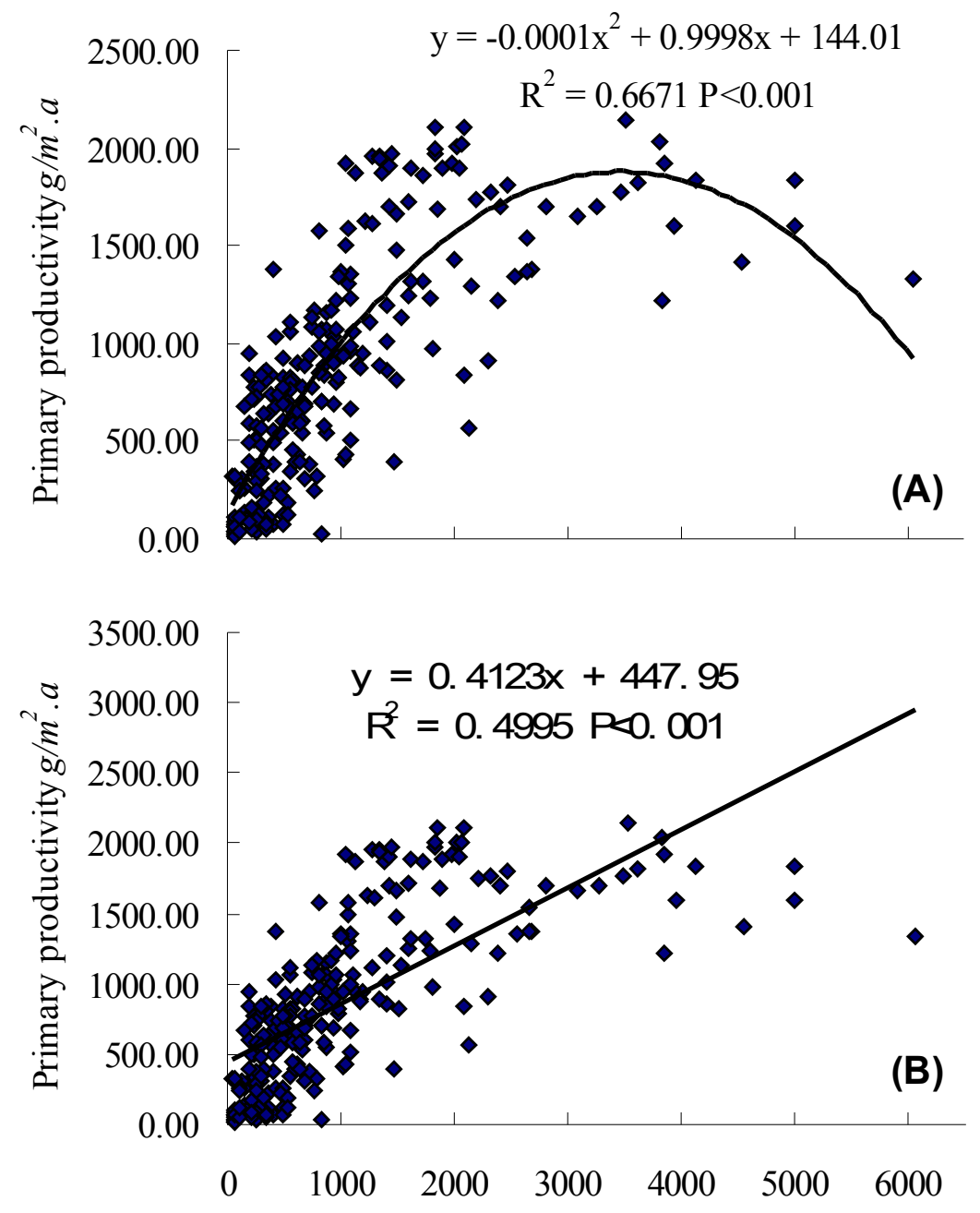

Species number of seed plant

Fig. 1 - Regression analysis between primary productivity of ecosystem and species richness of seed plant in the mainland of China. (A): quadratic model; (B): linear model. 
Fig. 2 - Regression analysis between species richness of bird and species richness of seed plant in the mainland of China. (A): quadratic model; (B): linear model.
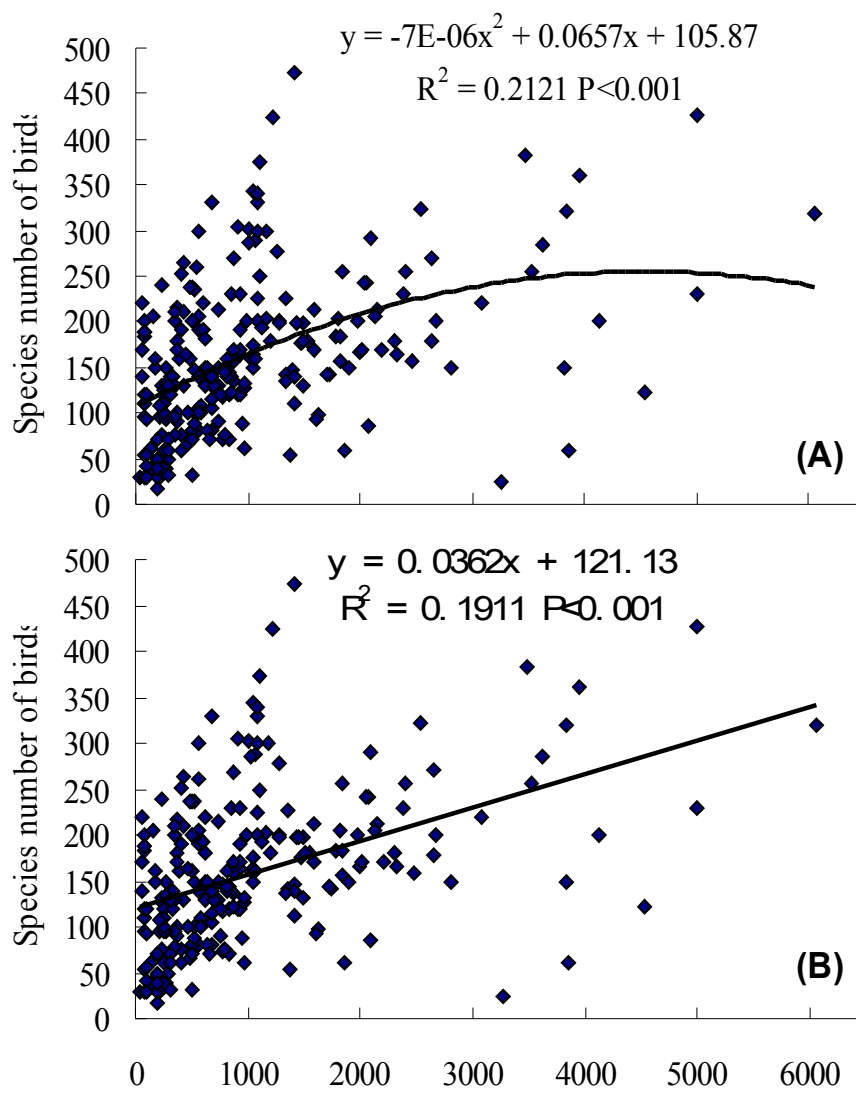

Species number of seed plant

Fig. 3 - Regression analysis between annual mean relative humidity of ecosystem and species richness of seed plant in the mainland of China. (A): quadratic model; (B): linear model.
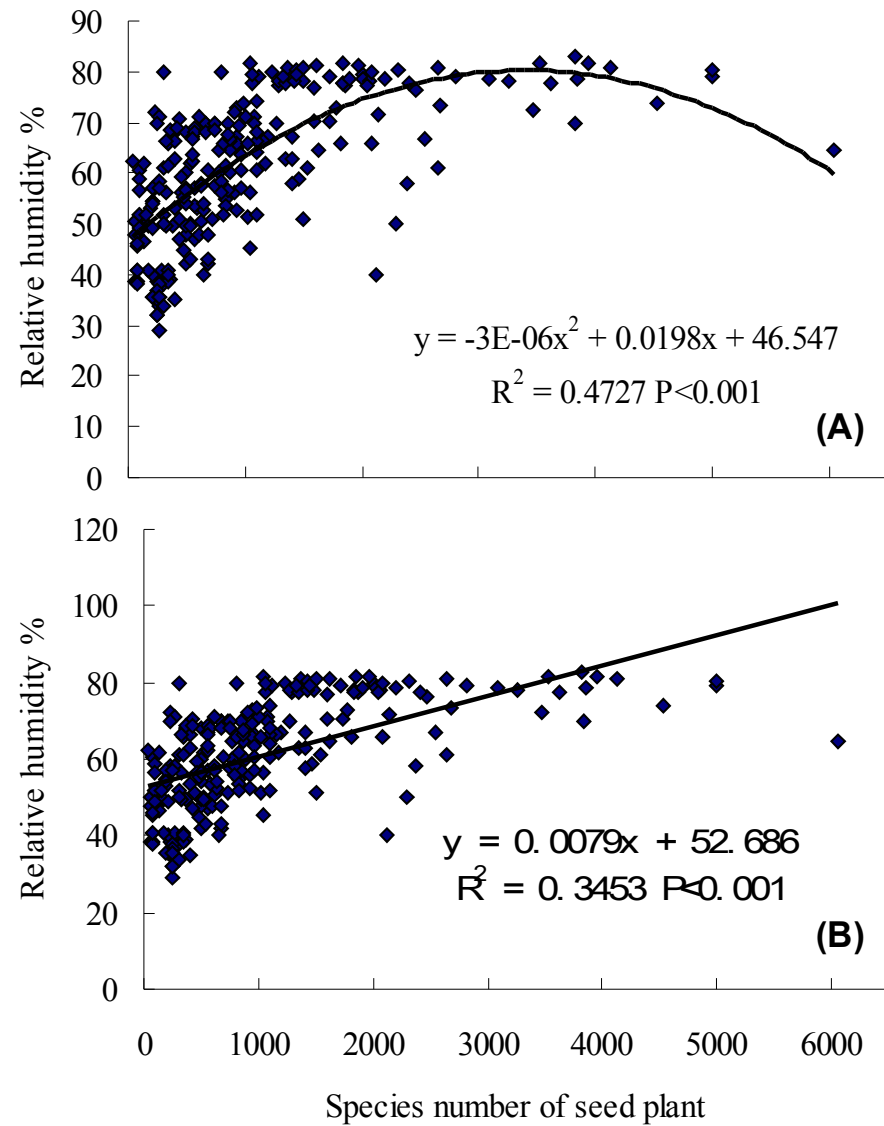

a rise in relative humidity, which reached a plateau at $80 \%$ relative humidity within 2000 species, and reached a maximum at 3500 seed plant species. Gradually, seed plant species richness over 4000 species was associated with lower relative humidity (Fig. $3)$. Therefore, the relationship between ecosystem relative humidity, and seed plant species richness was quadratic (hump-back).

\section{Discussion}

Primary productivity is the fundamental indicator of ecosystem function, and is at the base of ecosystem function (Díaz \& Cabido 2001, Hughes \& Petchey 2001, Partel et al. 2007, Zhang \& Zhang 2007). Animal species richness is typically associated with food plant availability, and the diversity of vegetation habitats in an ecosystem (Loreau 2001, Grime 1997). Therefore, animal species richness can be used as an indicator of ecosystem functioning, and bird species richness is particularly suitable to this purpose, as bird species diversity is dependent on species composition in a given ecosystem, horizontal and vertical habitat structure, patch mosaic structure, and ecosystem area (Zheng 2005, Hu et al. 2001). Relative humidity is a climatic index, which is related to some but not all climatic factors, including precipitation, wind, and temperature. However, humidity is also related to the ecosystem function, as it is related to ecosystem type, structure, and distribution area (Huston 1993, Tilman et al. 2001, Zhang et al. 2006). In low and medium precipitation regions, the humidity on sunny days depends largely on evaporation and transpiration ( $\mathrm{Li}$ et al. 1998, Hooper et al. 2005), therefore it is suitable to consider it as a proxy for ecosystem functioning. All three ecosystem function indicators on a large scale generated the same model; a linear model when plant species richness was under 5000 taxa, and quadratic model when plant species richness was over 5000. The regression analysis comparisons of the relationships between plant species richness and relative humidity, bird species richness, and primary productivity using linear and quadratic models with and without the three highest quadrats demonstrated that both models produced reasonable results (Tab. 1). This may suggest a rule for the relationship between biodiversity and ecosystem functioning at a large scale (Gillman \& Wright 2006).

The linear and hump-back relationships have been supported by several empirical studies, but showed variability at the small scale. Indeed, positive and negative curve patterns of biodiversity and ecosystem functions have previously been reported (Hector et al. 1999, Waide et al. 1999, Gillman \& Wright 2006). This may be due to the problems of scale (Mittelbach et al. 2001, Chase \& Leibold 2002), and the species richness 
gradient length. Experiments addressing a few species, monocultures, and mixtures are not comparable to the complexity of a natural ecosystem (Hillebrand \& Matthiessen 2009). Tilman et al. (2001) suggested the biological features of selected experimental species might exhibit one or more important influences on results. Another factor affecting results is species removal from study under natural conditions, mainly where the species is limited in number. In addition, grasses or herbaceous species are frequently used in these experiments, but woody species are excluded due to difficulties in cultivating woody taxa under greenhouse conditions. Most experiments at the small scale are carried out within one- or two-year time frame, and therefore historical and evolutionary effects are not evaluated. Large-scale biodiversity and ecosystem functioning studies are vital, and cannot be substituted by small scale experimental research (Chapin et al. 2000, Chase \& Leibold 2002).

Moreover, productivity is one indicator frequently assessed for ecosystem function in empirical studies. It is a viable parameter because productivity is the primary result of ecosystem function (Grace et al. 2007, Partel et al. 2007). However, it emphasizes the goods generated by ecosystems, but neglects to ascertain habitat functions yielded by wild plants and animals, and is not a comprehensive ecosystem measure. In our study, we used three ecosystem indicators, primary productivity, bird species richness, and relative humidity to comprehensively reflect ecosystem function (Loreau 2001). Primary productivity evaluates an ecosystem's capacity to produce biomass, bird species richness emphasizes the effects of ecosystem structure and the overall species pool on bird biodiversity, and relative humidity is an indicator of ecosystem capacity for balancing habitat conditions, stability, and service functions (Zhang \& Zhang 2007, Cadotte et al. 2009). Former studies suggest these three indicators characterize ecosystem function better than any single index. A similar response model for the three indicators to seed plant richness in mainland China ensured that the relationship of biodiversity and ecosystem functions was linear when the biodiversity gradient was comparatively short, and a hump-back model when the biodiversity gradient was at a larger scale.

\section{Acknowledgements}

The study was financially supported by the National Natural Science Foundation of China (Grants No. 31170494 and No. 30870399).

\section{References}

Akaike H (1974). A new look at the statistical model identification. IEEE Transactions on Automatic Control 19 (6): 716-723. - doi:
10.1109/TAC.1974.1100705

Begon M, Harper JL, Townsend CR (1996). Ecology: individual, population and communities. Blackwell Scientific, Boston, Massachusetts, USA.

Cadotte M, Cavender-Bares J, Tilman D (2009). Using phylogenetic, functional and trait diversity to understand patterns of plant community productivity. PLoS One 4 (5): 843-845. - doi: 10.1371/journal.pone.0005695

Chapin FS, Zavaleta ES, Eviners VT, Naylor RL, Vitousek PM, Reynolds HL (2000). Consequences of changing biodiversity. Nature 405 : 234-242. - doi: 10.1038/35012241

Chase JM, Leibold MA (2002). Spatial scale dictates the productivity-biodiversity relationship. Nature 416: 427-430. - doi: 10.1038/416427a

Chen LZ (1993). Biodiversity in China. Science Press, Beijing, China.

de Groot RS, Wilson MA, Boumans RMJ (2002). A typology for the classification, description and valuation of ecosystem functions, goods and services. Ecological Economics 41 (3): 393-408. doi: 10.1016/S0921-8009(02)00089-7

Díaz S, Cabido M (2001). Vive la différence: plant functional diversity matters to ecosystem processes. Trends in Ecology and Evolution 16 (11): 646-655. - doi: 10.1016/S0169-5347(01) 02283-2

Editor Committee of Fauna Sinica (1998). Fauna Sinica - Aves, vol. 1-14. Science Press, Beijing, China.

Foster B, Dickson TL, Murphy CA, Karel IS, Smith VH (2004). Propagule pools mediate community assembly and diversity-ecosystem regulation along a grassland productivity gradient. Journal of Ecology 92: 435-449. - doi: 10.1111/ j.0022-0477.2004.00882.x

Gillman LN, Wright SD (2006). The influence of productivity on the species richness of plants: a critical assessment. Ecology 87: 1234-1243. doi: $\quad 10.1890 / 0012-9658(2006) 87[1234: T I O P O$ $\mathrm{T}] 2.0 . \mathrm{CO} ; 2$

Grace JB (1999). The factors controlling species density in herbaceous plant communities: an assessment. Perspectives in Plant Ecology, Evolution and Systematics 2: 1-28. - doi: 10.1078/ 1433-8319-00063

Grace JB, Anderson TM, Smith MD, Seabloom E, Andelman SJ, Meche G, Weiher E, Allain LK, Jutila H, Sankaran M, Knops J, Ritchie M, Willig MR (2007). Does species diversity limit productivity in natural grassland communities? Ecology Letters 10 (8): 680-689. - doi: 10.1111/ j.1461-0248.2007.01058.x

Grime JP (1997). Biodiversity and ecosystem function: the debate deepens. Science 277: 12601261. - doi: 10.1126/science. 277.5330 .1260

Hector A, Schmid B, Beierkuhnlein C, Caldeira MC, Diemer M, Dimitrakopoulos PG (1999). Plant diversity and productivity experiments in European grasslands. Science 286: 1123-1127. doi: 10.1126/science.286.5442.1123

Hillebrand H, Matthiessen B (2009). Biodiversity in a complex world: consolidation and progress in functional biodiversity research. Ecology Let- ters 12: 1405-1419. - doi: 10.1111/j.1461-0248. 2009.01388.x

Hooper DU, Chapin FS, Ewel JJ, Hector A, Inchausti P, Lavorel S (2005). Effects of biodiversity on ecosystem functioning: a consensus of current knowledge. Ecological Monograph 75: 335. - doi: 10.1890/04-0922

$\mathrm{Hu}$ HJ, Jiang ZG, Wang ZW (2001). Correlation between avian and mammalian species richness in different geographic scales in China. Chinese Biodiversity 9 (2): 95-101.

Hughes JB, Petchey OL (2001). Merging perspectives on biodiversity and ecosystem functioning. Trends in Ecology and Evolution 16 (5): 222-223. - doi: 10.1016/S0169-5347(01)021279

Huston M (1993). Biological diversity, soils, and economics. Science 262: 1676-1680. - doi: 10.1126/science. 262.5140 .1676

Keddy P (2005). Putting the plants back into plant ecology: six pragmatic models for understanding and conserving plant diversity. Annals of Botany 96: 177-189. - doi: 10.1093/aob/mci166 Li DQ, Sun CY, Zhang XS (1998). Modelling the net primary productivity of the natural potential vegetation in China. Acta Botanica Sinica 40 (6): 560-566.

Lieth H, Box E (1972). Evapotranspiration and primary productivity. Publication in Climatology 25 (2): 37-46.

Loreau M (2001). Biodiversity and ecosystem functioning: current knowledge and future challenges. Science 294: 804-808. - doi: 10.1126/science. 1064088

Mittelbach GG, Steiner CF, Scheiner SM, Gross KL, Reynolds HL, Waide RB, Willig MR, Dodson SI, Gough L (2001). What is the observed relationship between species richness and productivity? Ecology 82: 2381-2396. - doi: 10.1890/0012-9658(2001)082[2381:WITORB] 2.0.CO;2

Northwest Research Institute of Botany (2000). Flora of Loess Plateau. Science Press, Beijing, China.

Partel M, Laanisto L, Zobel M (2007). Contrasting plant productivity-diversity relationships across latitude: the role of evolutionary history. Ecology 88 (5): 1091-1097. - doi: 10.1890/060997

Smith MD, Wilcox JC, Kelly T, Knapp AK (2004). Dominance not richness determines invasibility of tallgrass prairie. Oikos 106: 253262. - doi: 10.1111/j.0030-1299.2004.13057.x

Spehn EM, Hector A, Joshi J, Scherer-Lorenzen M, Schmid B, Bazeley-White E (2005). Ecosystem effects of biodiversity manipulations in European grasslands. Ecological Monograph 75: 37-63. - doi: 10.1890/03-4101

Suding KN, Miller AE, Bechtold H, Bowman WD (2006). The consequence of species loss on ecosystem nitrogen cycling depends on community compensation. Oecologia 149: 141-149. - doi: 10.1007/s00442-006-0421-4

Thompson K, Askew AP, Grime JP, Dunnett NP, Willis AJ (2005). Biodiversity, ecosystem function and plant traits in mature and immature 
plant communities. Functional Ecology 19: $355-$ 358. - doi: 10.1111/j.0269-8463.2005.00936.x

Tilman D, Reich PB, Knops J, Wedin D, Mielke T, Lehman C (2001). Diversity and productivity in a long-term grassland experiment. Science 294: 843-845. - doi: 10.1126/science.1060391 Waide RB, Willig MR, Steiner CF (1999). The relationship between productivity and species richness. Annual Review of Ecology and Systematics 30: 257-300. - doi: 10.1146/annurev.ecolsys.30. 1.257

Wu ZY (1980). Vegetation of China. Science Press, Beijing, China.
Wu ZY (1987). Flora of Tibet. Science Press, Beijing, China.

Wu ZY (2004). Flora of China, electronic version. Vol.5-82. Science Press, Beijing, China.

Zhang J-T (2002). A study on relations of vegetation, climate and soils in Shanxi province, China. Plant Ecology 162: 23-31. - doi: 10.1023/ A:1020355921982

Zhang J-T, Dong YR (2010). Factors affecting species diversity of plant communities and the restoration process in the loess area of China. Ecological Engineering 36: 345-350. - doi: 10.1016/ j.ecoleng.2009.04.001
Zhang J-T, Ru WM, Li B (2006). Relationships between vegetation and climate on the Loess Plateau in China. Folia Geobotanica 41: 151163. - doi: 10.1007/BF02806476

Zhang J-T, Zhang F (2007). Diversity and composition of plant functional groups in mountain forests of the Lishan Nature Reserve, North China. Botanical Studies 48: 339-348. [online] URL: http://ejournal.sinica.edu.tw/bbas/content/ 2007/3/Bot483-12.pdf

Zheng GM (2005). Classification and distribution of birds in China. Science Press, Beijing, China. 